\title{
Kinetics and mechanism of the anilinolysis of aryl phenyl isothiocyanophosphates in acetonitrile
}

Hasi Rani Barai and Hai Whang Lee*

\section{Full Research Paper}

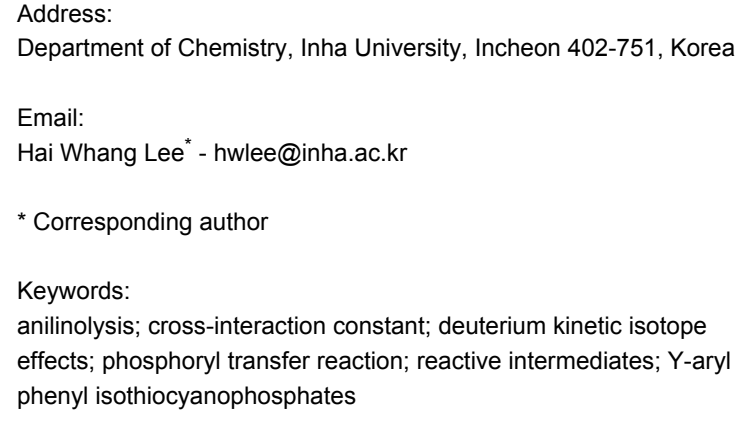

\author{
Beilstein J. Org. Chem. 2013, 9, 615-620. \\ doi:10.3762/bjoc.9.68 \\ Received: 10 December 2012 \\ Accepted: 06 March 2013 \\ Published: 26 March 2013 \\ This article is part of the Thematic Series "New reactive intermediates in \\ organic chemistry". \\ Guest Editor: G. Bucher
}

(C) 2013 Barai and Lee; licensee Beilstein-Institut.

License and terms: see end of document.

\begin{abstract}
Kinetic studies on the reactions of $\mathrm{Y}$-aryl phenyl isothiocyanophosphates with substituted $\mathrm{X}$-anilines and deuterated $\mathrm{X}$-anilines were carried out in acetonitrile at $55.0^{\circ} \mathrm{C}$. The free-energy relationships with $\mathrm{X}$ in the nucleophiles were biphasic concave upwards with a break region between $\mathrm{X}=\mathrm{H}$ and 4-Cl, giving unusual positive $\rho_{X}$ and negative $\beta_{X}$ values with less basic anilines $(X=4-C l$ and 3-Cl). A stepwise mechanism with rate-limiting bond breaking for more basic anilines and with rate-limiting bond formation for less basic anilines is proposed based on the positive and negative $\rho_{\mathrm{XY}}$ values, respectively. The deuterium kinetic isotope effects involving deuterated anilines $\left(\mathrm{XC}_{6} \mathrm{H}_{4} \mathrm{ND}_{2}\right)$ showed primary normal and secondary inverse DKIEs for more basic and less basic anilines, rationalized by frontside attack involving hydrogen-bonded four-center-type TSf and backside attack TSb, respectively. The positive $\rho_{X}$ values with less basic anilines are substantiated by the tight TS, in which the extent of the bond formation is great and the degree of the bond breaking is considerably small.
\end{abstract}

\section{Introduction}

The nucleophilic substitution reactions of tetracoordinate phosphorus have been studied extensively, experimentally and theoretically, in our lab. Two main types of displacement processes are well known in neutral phosphoryl transfer reactions: a stepwise mechanism involving a trigonal bipyramidal pentacoordinate (TBP-5C) intermediate and a concerted displacement at phosphorus through a single pentacoordinate tran- sition state (TS). To extend the kinetic studies on the phosphoryl transfer reactions, the reactions of $\mathrm{Y}$-aryl phenyl isothiocyanophosphates $(\mathbf{1 a}-\mathbf{e})$ with substituted anilines $\left(\mathrm{XC}_{6} \mathrm{H}_{4} \mathrm{NH}_{2}\right)$ and deuterated anilines $\left(\mathrm{XC}_{6} \mathrm{H}_{4} \mathrm{ND}_{2}\right)$ have been investigated kinetically in acetonitrile $(\mathrm{MeCN})$ at $55.0 \pm 0.1{ }^{\circ} \mathrm{C}$ (Scheme 1). The kinetic results of the present work are discussed based on the selectivity parameters and deuterium kinetic isotope effects 


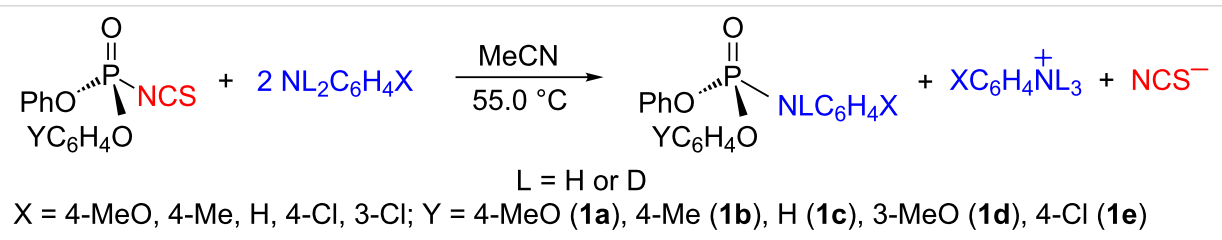

Scheme 1: Reactions of $Y$-aryl phenyl isothiocyanophosphates (1a-e) with $\mathrm{XC}_{6} \mathrm{H}_{4} \mathrm{NH}_{2}(\mathrm{D})_{2}$ in $\mathrm{MeCN}$ at $55.0^{\circ} \mathrm{C}$.

(DKIEs). The aim of this work is to gain further information on the substituent effects, DKIEs and mechanism of the phosphoryl transfer reactions.

\section{Results and Discussion}

Table 1 summarizes the second-order rate constants, $k_{\mathrm{H}}$ and $k_{\mathrm{D}}$, with $\mathrm{X}$-anilines and deuterated $\mathrm{X}$-anilines, respectively. Table 2 and Table 3 summarize the Hammett $\left(\rho_{\mathrm{X}(\mathrm{H} \text { and } \mathrm{D})}\right)$ and Brönsted $\left(\beta_{\mathrm{X}(\mathrm{H} \text { and } \mathrm{D})}\right)$ coefficients with $\mathrm{X}$, and Hammett coefficients $\left(\rho_{\mathrm{Y}(\mathrm{H})}\right)$ with $\mathrm{Y}$, respectively. The second-order rate constants were obtained from the slopes of pseudo-first-order rate constants $\left(k_{\text {obsd }}\right)$ versus aniline concentration (Equation 1). Base-catalysis or noticeable side reactions could be safely ruled out from the zero intercept, $k_{0} \approx 0$, in $\mathrm{MeCN}$.

$$
k_{\text {obsd }}=k_{0}+k_{\mathrm{H}(\mathrm{D})}\left[\mathrm{XC}_{6} \mathrm{H}_{4} \mathrm{NH}_{2}(\mathrm{D})_{2}\right]
$$

Figure 1 presents the Brönsted plots with $\mathrm{X}$ in the nucleophiles. The substituent effects of $\mathrm{X}$ on the reaction rates are not

\begin{tabular}{|c|c|c|c|c|c|c|}
\hline$X \backslash Y$ & & $4-\mathrm{MeO}(\mathbf{1 a})$ & 4-Me (1b) & $\mathrm{H}(\mathbf{1 c})$ & 3-MeO (1d) & $4-\mathrm{Cl}(1 \mathrm{e})$ \\
\hline \multirow[t]{2}{*}{ 4-MeO } & $k_{\mathrm{H}}$ & $9.58 \pm 0.02^{\mathrm{a}}$ & $10.2 \pm 0.1$ & $12.7 \pm 0.1$ & $17.2 \pm 0.1$ & $27.5 \pm 0.1$ \\
\hline & $k_{\mathrm{D}}$ & $7.15 \pm 0.04$ & - & $8.92 \pm 0.01$ & - & $18.7 \pm 0.1$ \\
\hline \multirow[t]{2}{*}{ 4-Me } & $k_{\mathrm{H}}$ & $2.71 \pm 0.01$ & $3.02 \pm 0.01$ & $4.38 \pm 0.01$ & $6.09 \pm 0.03$ & $9.51 \pm 0.01$ \\
\hline & $k_{\mathrm{D}}$ & $2.30 \pm 0.01$ & - & $3.44 \pm 0.02$ & - & $7.27 \pm 0.05$ \\
\hline \multirow[t]{2}{*}{$\mathrm{H}$} & $k_{\mathrm{H}}$ & $0.400 \pm 0.001$ & $0.517 \pm 0.005$ & $0.693 \pm 0.004$ & $1.04 \pm 0.01$ & $1.89 \pm 0.01$ \\
\hline & $k_{\mathrm{D}}$ & $0.384 \pm 0.001$ & - & $0.647 \pm 0.001$ & - & $1.67 \pm 0.01$ \\
\hline \multirow[t]{2}{*}{$4-\mathrm{Cl}$} & $k_{\mathrm{H}}$ & $0.206 \pm 0.001$ & $0.257 \pm 0.001$ & $0.434 \pm 0.001$ & $0.787 \pm 0.005$ & $1.67 \pm 0.01$ \\
\hline & $k_{\mathrm{D}}$ & $0.244 \pm 0.001$ & - & $0.492 \pm 0.001$ & - & $1.81 \pm 0.02$ \\
\hline \multirow[t]{2}{*}{$3-\mathrm{Cl}$} & $k_{\mathrm{H}}$ & $0.718 \pm 0.002$ & $0.886 \pm 0.008$ & $1.48 \pm 0.01$ & $2.68 \pm 0.01$ & $5.62 \pm 0.03$ \\
\hline & $k_{\mathrm{D}}$ & $0.994 \pm 0.002$ & - & $2.12 \pm 0.01$ & - & $8.46 \pm 0.04$ \\
\hline
\end{tabular}

astandard deviation.

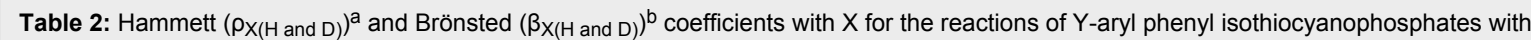
$\mathrm{XC}_{6} \mathrm{H}_{4} \mathrm{NH}_{2}\left(\mathrm{D}_{2}\right)$ in $\mathrm{MeCN}$ at $55.0^{\circ} \mathrm{C}$.

\begin{tabular}{|c|c|c|c|c|c|c|}
\hline$X \backslash Y$ & & 4-MeO (1a) & 4-Me (1b) & $H(1 c)$ & 3-MeO (1d) & $4-\mathrm{Cl}(1 \mathrm{e})$ \\
\hline \multirow[t]{4}{*}{ 4-MeO, 4-Me, H } & $\rho_{X(H)}{ }^{c}$ & $-5.09 \pm 0.03$ & $-4.76 \pm 0.04$ & $-4.68 \pm 0.01$ & $-4.51 \pm 0.01$ & $-4.29 \pm 0.02$ \\
\hline & $\rho_{X(D)}{ }^{c}$ & $-4.69 \pm 0.02$ & - & $-4.23 \pm 0.01$ & - & $-3.87 \pm 0.02$ \\
\hline & $\beta_{X(H)}{ }^{c}$ & $1.83 \pm 0.08$ & $1.72 \pm 0.09$ & $1.69 \pm 0.04$ & $1.63 \pm 0.04$ & $1.55 \pm 0.07$ \\
\hline & $\beta \times(D)^{c}$ & $1.69 \pm 0.06$ & - & $1.53 \pm 0.04$ & - & $1.40 \pm 0.06$ \\
\hline \multirow[t]{4}{*}{$4-\mathrm{Cl}, 3-\mathrm{Cl}$} & $\rho \times(H)$ & 3.87 & 3.84 & 3.81 & 3.80 & 3.76 \\
\hline & $\rho_{X(D)}$ & 4.35 & - & 4.53 & - & 4.78 \\
\hline & $\beta_{X(H)}$ & -1.18 & -1.17 & -1.16 & -1.16 & -1.15 \\
\hline & $\beta \times(D)$ & -1.33 & - & -1.38 & - & -1.46 \\
\hline
\end{tabular}

aThe $\sigma$ values were taken from [1]. ${ }^{b}$ The $\mathrm{p} K_{\mathrm{a}}$ values of X-anilines in water were taken from [2]. ${ }^{\mathrm{c}}$ Correlation coefficients $(r)$ of $\rho_{X}$ and Brönsted $\beta_{X}$ values for $\mathrm{X}=(4-\mathrm{MeO}, 4-\mathrm{Me}, \mathrm{H})$ are better than 0.996 . 
Table 3: Hammett coefficients $\left(\rho_{Y(H)}\right)^{a}$ with $\mathrm{Y}$ for the reactions of $\mathrm{Y}$-aryl phenyl isothiocyanophosphates with $\mathrm{XC}_{6} \mathrm{H}_{4} \mathrm{NH}_{2}$ in $\mathrm{MeCN}$ at $55.0{ }^{\circ} \mathrm{C}$.

\begin{tabular}{ccccr}
$X$ & $4-\mathrm{MeO}$ & $4-\mathrm{Me}$ & $\mathrm{H}$ & $4-\mathrm{Cl}$ \\
\hline$\left.\rho_{Y(H)}\right)^{b}$ & $0.88 \pm 0.07$ & $1.08 \pm 0.05$ & $1.27 \pm 0.07$ & $1.77 \pm 0.09$ \\
\hline
\end{tabular}

${ }^{a}$ The $\sigma$ values were taken from [1]. ${ }^{b}$ Correlation coefficients $(r)$ of $\rho_{Y}(\mathrm{H})$ values are better than 0.962 .

compatible with a typical nucleophilic substitution reaction. The Hammett and Brönsted plots with $\mathrm{X}$ are biphasic concave upwards with a break region between $\mathrm{X}=\mathrm{H}$ and 4-Cl (break point of $\sigma_{X} \approx 0.13$ ), giving unusual positive $\rho_{X}$ and negative $\beta_{X}$ values with $\mathrm{X}=4-\mathrm{Cl}$ and $3-\mathrm{Cl}$. Positive $\rho_{\mathrm{X}}$ (and negative $\beta_{\mathrm{X}}$ )

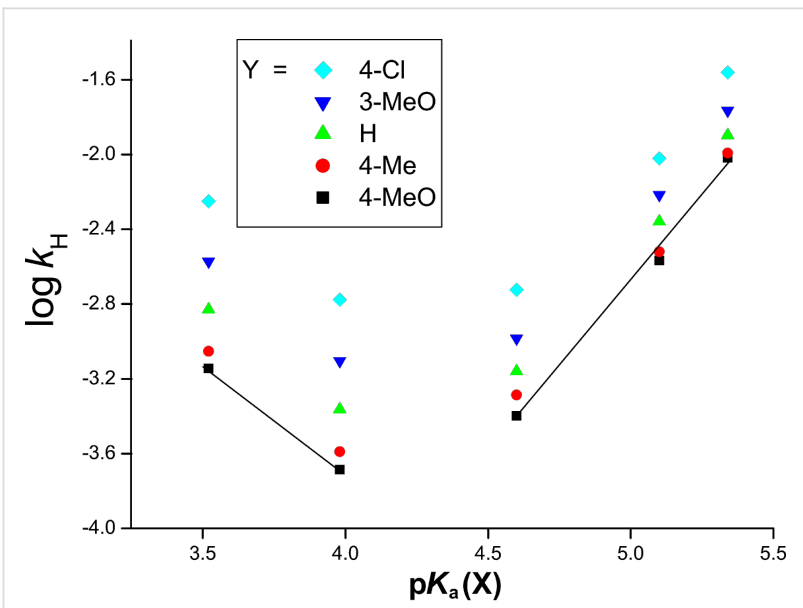

Figure 1: Brönsted plots with $X$ [log $k_{\mathrm{H}}$ versus $\left.\mathrm{p} K_{\mathrm{a}}(\mathrm{X})\right]$ of the reactions of $\mathrm{Y}$-aryl phenyl isothiocyanophosphates with $\mathrm{XC}_{6} \mathrm{H}_{4} \mathrm{NH}_{2}$ in $\mathrm{MeCN}$ at $55.0^{\circ} \mathrm{C}$.

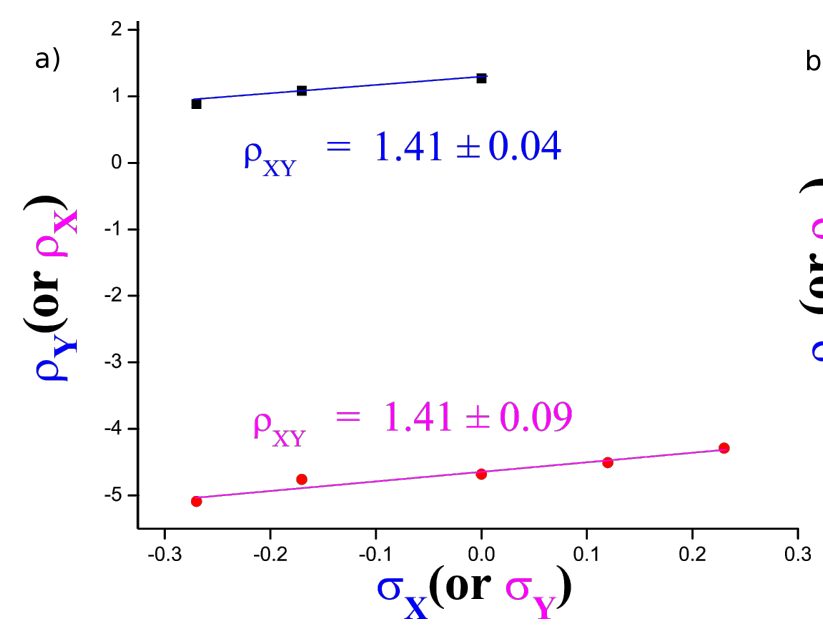

values indicate that the nucleophilic $\mathrm{N}$ atom becomes more negative in the TS compared to in the ground state (GS). The substituent effects of $\mathrm{Y}$ on the reaction rates are consistent with a typical nucleophilic substitution reaction, and the rate increases with a more electron-withdrawing substituent.

The cross-interaction constant (CIC) is defined based on the substituent effects of the nucleophiles, substrates and/or leaving groups on the reaction rates [3-5]. In the present work, the CIC $\left(\rho_{\mathrm{XY}}\right)$ between substituents $\mathrm{X}$ and $\mathrm{Y}$ in the nucleophiles and substrates, respectively, is described in Equation 2 and Equation 3 .

$$
\begin{aligned}
& \log \left(k_{\mathrm{XY}} / k_{\mathrm{HH}}\right)=\rho_{\mathrm{X}} \sigma_{\mathrm{X}}+\rho_{\mathrm{Y}} \sigma_{\mathrm{Y}}+\rho_{\mathrm{XY}} \sigma_{\mathrm{X}} \sigma_{\mathrm{Y}} \\
& \rho_{\mathrm{XY}}=\partial^{2} \log \left(k_{\mathrm{XY}} / k_{\mathrm{HH}}\right) / \partial \sigma_{\mathrm{X}} \partial \sigma_{\mathrm{Y}} \\
&=\partial \rho_{\mathrm{X}} / \partial \sigma_{\mathrm{Y}} \\
&=\partial \rho_{\mathrm{Y}} / \partial \sigma_{\mathrm{X}}
\end{aligned}
$$

The two $\rho_{X Y}$ values are obtained because the Hammett plots with $X$ are biphasic. Figure 2 shows the plots of $\rho_{X}$ versus $\sigma_{Y}$

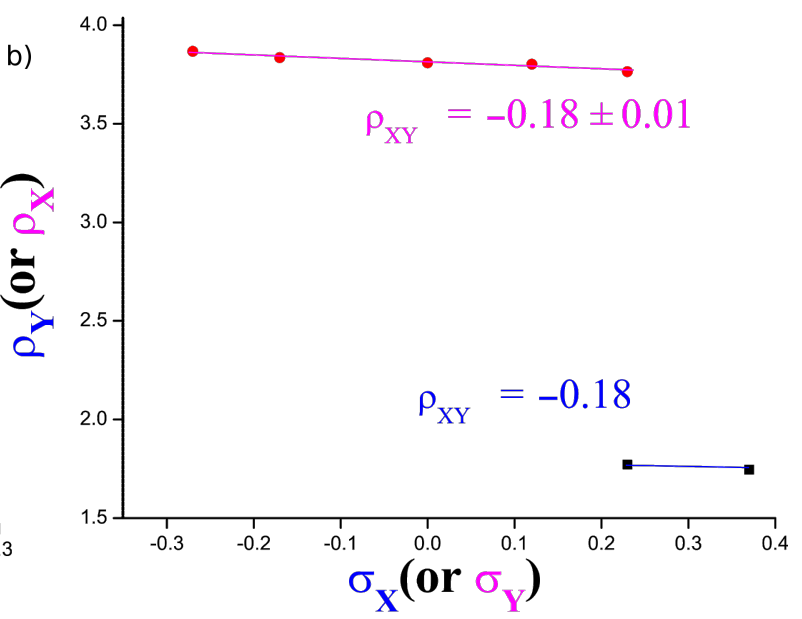

Figure 2: Plots of $\rho_{X}$ versus $\sigma_{Y}$ and $\rho_{Y}$ versus $\sigma_{X}$ of the reactions of $Y$-aryl phenyl isothiocyanophosphates with $X_{6} \mathrm{H}_{4} \mathrm{NH}_{2}$ in $\mathrm{MeCN}$ at $55.0{ }^{\circ} \mathrm{C}$. The obtained $\rho_{X Y}$ values by multiple regression are as follows: (a) $\rho_{X Y}=1.40 \pm 0.06(r=0.992)$ with more basic anilines and $(b) \rho_{X Y}=-0.18 \pm 0.09$ $(r=0.975)$ with less basic anilines. 
and $\rho_{Y}$ versus $\sigma_{X}$ to determine the $\rho_{X Y}$ values, according to Equation 3 . The signs of $\rho_{X Y}$ are positive with more basic anilines $(\mathrm{X}=4-\mathrm{MeO}, 4-\mathrm{Me}, \mathrm{H})$ but negative with less basic anilines $(\mathrm{X}=4-\mathrm{Cl}, 3-\mathrm{Cl})$. The number of kinetic data points, $10 k_{\mathrm{H}}$ values with less basic anilines, to obtain the $\rho_{\mathrm{XY}}$ value is not enough to overcome the experimental error. At least, however, the sign of $\rho_{X Y}$ is acceptable, and the greater magnitude of $\rho_{X Y}$ value with more basic anilines than that with less basic anilines is also acceptable. Accordingly, the authors propose the following reaction mechanism: (i) a stepwise process with rate-limiting leaving-group departure from the intermediate for more basic anilines based on the positive sign of $\rho_{X Y}(=1.40)$, and (ii) a stepwise process with rate-limiting bond formation for less basic anilines based on the negative sign of $\rho_{X Y}(=-0.18)$ [3-5]. The greater magnitude of $\rho_{X Y}$ value with more basic anilines compared to that with less basic anilines suggests that the interaction between $\mathrm{X}$ and $\mathrm{Y}$ with more basic anilines is larger than that with less basic anilines in the TS (see below).

The DKIEs are primary normal with more basic anilines ( $\mathrm{X}=4-\mathrm{MeO}, 4-\mathrm{Me}, \mathrm{H}$ ) while secondary inverse with less basic anilines $(\mathrm{X}=4-\mathrm{Cl}, 3-\mathrm{Cl})$ as shown in Table 4. Primary normal DKIEs $\left(k_{\mathrm{H}} / k_{\mathrm{D}}>1.0\right)$ indicate that partial deprotonation of the aniline occurs in a rate-limiting step by hydrogen bonding [6-12]. In contrast, secondary inverse DKIEs $\left(k_{\mathrm{H}} / k_{\mathrm{D}}<1.0\right)$ indicate that the $\mathrm{N}-\mathrm{H}(\mathrm{D})$ vibrational frequencies invariably increase upon going to the TS because of an increase in the steric congestion in the bond-making process in a stepwise process with a rate-limiting bond formation (or a normal $\mathrm{S}_{\mathrm{N}} 2$ reaction) [13-15]. The magnitudes of the $k_{\mathrm{H}} / k_{\mathrm{D}}$ values invariably decrease as the aniline becomes less basic. The magnitudes of the $k_{\mathrm{H}} / k_{\mathrm{D}}$ values invariably increase for $\mathrm{X}=(4-\mathrm{MeO}, 4-\mathrm{Me}, \mathrm{H}$, 4-Cl) while they invariably decrease for $\mathrm{X}=3-\mathrm{Cl}$ as the substituent $\mathrm{Y}$ changes from electron-donating to electron-withdrawing. The maximum value of $k_{\mathrm{H}} / k_{\mathrm{D}}=1.47$ with $\mathrm{X}=4-\mathrm{MeO}$ and $\mathrm{Y}=4-\mathrm{Cl}$ indicates extensive hydrogen bonding whereas the minimum value of $k_{\mathrm{H}} / k_{\mathrm{D}}=0.66$ with $\mathrm{X}=3-\mathrm{Cl}$ and $\mathrm{Y}=4-\mathrm{Cl}$ indicates severe steric congestion in the TS, suggesting a great extent of bond formation. The secondary inverse and primary normal DKIEs are substantiated by backside nucleophilic attack involving in-line-type TSb and frontside attack involving hydrogen-bonded, four-center-type TSf, respectively (Scheme 2).

The hydrogen-bonded four-center type of TSb-H could be another plausible TS structure, in which hydrogen bonding of an amine hydrogen atom occurs on the $\mathrm{P}=\mathrm{O}$ oxygen atom (Scheme 3). In the present work, three possible TSs could substantiate the primary normal DKIEs: (i) TSf, (ii) TSb-H or (iii) both TSb-H and TSf. The anilinolyses of tetracoordinate
Table 4: The DKIEs $\left(k_{H} / k_{\mathrm{D}}\right)$ of the reactions of $\mathrm{Y}$-aryl phenyl isothiocyanophosphates with $\mathrm{XC}_{6} \mathrm{H}_{4} \mathrm{NH}(\mathrm{D})_{2}$ in $\mathrm{MeCN}$ at $55.0^{\circ} \mathrm{C}$.

\begin{tabular}{lccc}
$\mathrm{X} \backslash \mathrm{Y}$ & $4-\mathrm{MeO}(\mathbf{1 a})$ & $\mathrm{H}(\mathbf{1 c})$ & $4-\mathrm{Cl}(\mathbf{1 e})$ \\
\hline $4-\mathrm{MeO}$ & $1.34 \pm 0.01^{\mathrm{a}}$ & $1.42 \pm 0.01$ & $1.47 \pm 0.01$ \\
$4-\mathrm{Me}$ & $1.18 \pm 0.01$ & $1.27 \pm 0.01$ & $1.31 \pm 0.01$ \\
$\mathrm{H}$ & $1.04 \pm 0.01$ & $1.07 \pm 0.01$ & $1.13 \pm 0.01$ \\
$4-\mathrm{Cl}$ & $0.844 \pm 0.005$ & $0.882 \pm 0.003$ & $0.922 \pm 0.012$ \\
$3-\mathrm{Cl}$ & $0.722 \pm 0.002$ & $0.698 \pm 0.001$ & $0.664 \pm 0.004$ \\
\hline
\end{tabular}

aStandard error $\left\{=1 / k_{D}\left[\left({ }^{\Delta} k_{H}\right)^{2}+\left(k_{H} / k_{D}\right)^{2} \times\left({ }^{\Delta} k_{D}\right)^{2}\right]^{1 / 2}\right\}$ from [16].

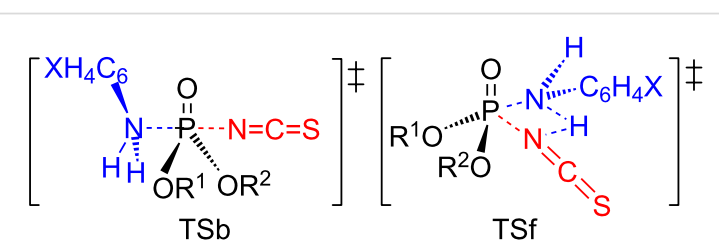

Scheme 2: Backside attack involving in-line-type TSb and frontside attack involving a hydrogen-bonded, four-center-type TSf.

phosphorus with the $\mathrm{Cl}^{-}$leaving group have been extensively studied in this lab, and the obtained data of primary normal DKIEs involving deuterated anilines are rationalized by TSftype in which hydrogen bonding of an amine hydrogen atom occurs on the departing chloride [17-23]. The authors also suggested TSf-type, in which hydrogen bonding of an amine hydrogen atom occurs to the departing phenoxy oxygen atom for the anilinolyses of aryl dimethyl, methyl and diphenyl phosphinates [24]. Thus, at this point, the authors are in favor of TSf for the present work.

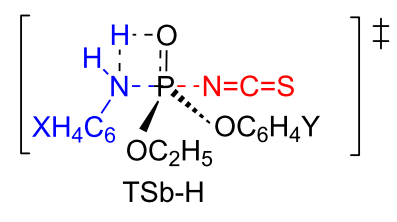

Scheme 3: Backside attack involving a hydrogen-bonded, four-centertype $\mathrm{TSb}-\mathrm{H}$.

The focus will now shift to the unusual positive $\rho_{X}$ and negative $\beta_{X}$ values with $\mathrm{X}=4-\mathrm{Cl}$ and $3-\mathrm{Cl}$. These values can be observed because of (i) desolvation of the GS $[25,26]$ or (ii) TS imbalance phenomenon [27-29]. However, in the present work, the positive $\rho_{X}$ and negative $\beta_{X}$ values for less basic anilines are not ascribed to (i) a desolvation step prior to the rate-limiting nucleophilic attack, because the aniline nucleophile is neutral and the MeCN solvent is dipolar aprotic; and to (ii) a TS imbalance phenomenon, because the leaving group of isothiocyanate 
is too poor to form an ion-pair type. The unusual positive $\rho_{X}$ (and negative $\left.\beta_{X}\right)$ values with $\mathrm{X}=(4-\mathrm{Cl}$ and $3-\mathrm{Cl})$ indicate that the nucleophilic $\mathrm{N}$ atom becomes more negative in the TS compared to in the GS. The authors, thus, propose that the structure of the TS is similar to what would be if the isothiocyante were the nucleophile and aniline were the leaving group, such that the nucleophilic $\mathrm{N}$ atom becomes more negative in the TS compared to in the GS. In other words, the TS is very tight and in which the degree of bond formation is very great while the degree of bond breaking is considerably small, resulting in the positive $\rho_{\mathrm{X}}$. The very small value of $k_{\mathrm{H}} / k_{\mathrm{D}}=0.66$ with $\mathrm{X}=3-\mathrm{Cl}$ and $\mathrm{Y}=4-\mathrm{Cl}$ could be supporting evidence. The relatively small magnitude of $\rho_{X Y}=-0.18$ with less basic anilines could be another piece of supporting evidence, because the normal $\mathrm{S}_{\mathrm{N}} 2$ mechanism (or stepwise mechanism with ratelimiting bond formation) gives a magnitude of $\rho_{X Y} \approx-0.7$ [3-5]. This would be attributed to the strong interaction between the nucleophile (X) and leaving group over the nucleophile (X) and substrate (Y) (see above).

Finally, the authors propose the following reaction mechanism of the present work: (i) for more basic anilines $(\mathrm{X}=4-\mathrm{MeO}$, 4-Me, $\mathrm{H}$ ), a stepwise process with rate-limiting leaving-group departure from the intermediate, involving a predominant frontside attack with a hydrogen-bonded four-center-type TSf based on the positive $\rho_{X Y}$ and primary normal DKIEs; and (ii) for less basic anilines $(\mathrm{X}=4-\mathrm{Cl}, 3-\mathrm{Cl})$, a stepwise process with rate-limiting bond formation, involving a predominant backside attack TSb, and very tight TS, in which the extent of the bond formation is great and the degree of bond breaking is very small based on the negative $\rho_{X Y}$, secondary inverse DKIEs and positive $\rho_{X}$.

Activation parameters, enthalpies and entropies of activation, are determined as shown in Table 5. The enthalpies of activation are relatively low and entropies of activation are of relatively large negative value. The relatively low value of activation enthalpy and large negative value of activation entropy are typical for the aminolyses of $\mathrm{P}=\mathrm{O}$ systems, regardless of the mechanism, whether stepwise with rate-limiting bond formation (or a concerted) or stepwise with rate-limiting bond breaking.

\section{Experimental}

Materials. HPLC grade acetonitrile (water content is less than $0.005 \%$ ) was used without further purification. Deuterated anilines were synthesized as previously described [17-24]. Substrates were prepared as described earlier [30].

Kinetics measurement. Rates were measured conductometrically at $55.0^{\circ} \mathrm{C}$ as described previously [17-24]. The initial
Table 5: Activation parameters for the reactions of $\mathrm{Y}$-aryl phenyl isothiocyanophosphate with aniline $\left(\mathrm{C}_{6} \mathrm{H}_{5} \mathrm{NH}_{2}\right)$ in $\mathrm{MeCN}$.

\begin{tabular}{|c|c|c|c|c|}
\hline$Y$ & $t /{ }^{\circ} \mathrm{C}$ & $k_{\mathrm{H}} \times 10^{4} / \mathrm{M}^{-1} \mathrm{~s}^{-1}$ & $\begin{array}{c}\Delta H^{\neq} / \mathrm{kcal} \\
\mathrm{mol}^{-1}\end{array}$ & $\begin{array}{c}-\Delta S^{\neq} / \mathrm{cal} \\
\mathrm{mol}^{-1} K^{-1}\end{array}$ \\
\hline \multirow[t]{3}{*}{ 4-MeO (1a) } & 45.0 & $2.91 \pm 0.01$ & $5.7 \pm 0.1$ & $56 \pm 1$ \\
\hline & 55.0 & $4.00 \pm 0.01$ & & \\
\hline & 65.0 & $5.29 \pm 0.07$ & & \\
\hline \multirow[t]{3}{*}{ 4-Me (1b) } & 45.0 & $3.72 \pm 0.01$ & $6.2 \pm 0.1$ & $55 \pm 1$ \\
\hline & 55.0 & $5.17 \pm 0.05$ & & \\
\hline & 65.0 & $7.08 \pm 0.01$ & & \\
\hline \multirow[t]{3}{*}{$H(1 c)$} & 45.0 & $4.96 \pm 0.01$ & $6.3 \pm 0.1$ & $54 \pm 1$ \\
\hline & 55.0 & $6.93 \pm 0.01$ & & \\
\hline & 65.0 & $9.51 \pm 0.01$ & & \\
\hline \multirow[t]{3}{*}{ 3-MeO (1d) } & 45.0 & $7.24 \pm 0.01$ & $6.2 \pm 0.4$ & $54 \pm 1$ \\
\hline & 55.0 & $10.4 \pm 0.1$ & & \\
\hline & 65.0 & $13.7 \pm 0.1$ & & \\
\hline \multirow[t]{3}{*}{$4-\mathrm{Cl}(1 \mathrm{e})$} & 45.0 & $13.5 \pm 0.1$ & $6.1 \pm 0.1$ & $53 \pm 1$ \\
\hline & 55.0 & $18.9 \pm 0.1$ & & \\
\hline & 65.0 & $25.5 \pm 0.2$ & & \\
\hline
\end{tabular}

concentrations of substrates and nucleophiles were as follows; [substrate $]=5 \times 10^{-3} \mathrm{M}$ and $[\mathrm{X}$-aniline $]=0.10-0.30 \mathrm{M}$. The second-order rate constants $\left(k_{\mathrm{H}(\mathrm{D})}\right)$ were determined for at least five concentrations of anilines. The $k_{\text {obsd }}$ values were the average of at least three runs.

Product analysis. Diphenyl isothiocyanophosphate was reacted with excess aniline for more than 15 half-lives at $55.0^{\circ} \mathrm{C}$ in $\mathrm{MeCN}$. Acetonitrile was evaporated under reduced pressure. The product mixture was treated with ether by a work-up process with dilute $\mathrm{HCl}$ and dried over anhydrous $\mathrm{MgSO}_{4}$. The product was isolated through column chromatography $(30 \%$ ethyl acetate $/ n$-hexane) and then dried under reduced pressure. The analytical and spectroscopic data of the product gave the following results (see also Supporting Information File 1):

$\left[\left(\mathbf{C}_{6} \mathrm{H}_{5} \mathrm{O}\right)_{2} \mathbf{P}(=\mathbf{O}) \mathbf{N H C}_{6} \mathrm{H}_{5}\right]$. White solid crystal; $\mathrm{mp}$ 132-133 ${ }^{\circ} \mathrm{C}$; ${ }^{1} \mathrm{H}$ NMR $\left(400 \mathrm{MHz}, \mathrm{MeCN}-d_{3}\right) \delta 6.66$ (br d, $J=8.8 \mathrm{~Hz}, 1 \mathrm{H}$, aliphatic), 7.01-7.43 (m, 15H, aromatic); ${ }^{13} \mathrm{C}$ NMR (100 MHz, MeCN-d $\left.d_{3}\right) \delta 118.59-131.20$ (m, 18C; aromatic); ${ }^{31} \mathrm{P}$ NMR (162 MHz, MeCN-d $\left.d_{3}\right) \delta 3.62(\mathrm{~d}$, $J=8.6 \mathrm{~Hz}, 1 \mathrm{P}, \mathrm{P}=\mathrm{O})$; GC-MS (EI, $m / z): 325\left(\mathrm{M}^{+}\right)$.

\section{Supporting Information}

\section{Supporting Information File 1}

Spectra of product.

[http://www.beilstein-journals.org/bjoc/content/

supplementary/1860-5397-9-68-S1.pdf] 


\section{Acknowledgements}

This work was supported by the Inha University Research Fund.

\section{References}

1. Hansch, C.; Leo, A.; Taft, R. W. Chem. Rev. 1991, 91, 165-195. doi:10.1021/cr00002a004

2. Streitwieser, A.; Heathcock, C. H.; Kosower, E. M. Introduction to Organic Chemistry, 4th ed.; Macmillan: New York, NY, 1992; p 735.

3. Lee, I. Chem. Soc. Rev. 1990, 19, 317-333. doi:10.1039/cs9901900317

4. Lee, I. Adv. Phys. Org. Chem. 1991, 27, 57-117. doi:10.1016/S0065-3160(08)60064-7

5. Lee, I.; Lee, H. W. Collect. Czech. Chem. Commun. 1999, 64, 1529-1550. doi:10.1135/cccc19991529

6. Lee, I.; Koh, H. J.; Lee, B.-S.; Lee, H. W. J. Chem. Soc., Chem. Commun. 1990, 335-336. doi:10.1039/C39900000335

7. Barnes, J. A.; Williams, I. H. J. Chem. Soc., Chem. Commun. 1993, 1286-1287. doi:10.1039/C39930001286

8. Lee, I. Chem. Soc. Rev. 1995, 24, 223-229. doi:10.1039/cs9952400223

9. Marlier, J. F. Acc. Chem. Res. 2001, 34, 283-290. doi:10.1021/ar000054d

10. Westaway, K. C. Adv. Phys. Org. Chem. 2006, 41, 217-273. doi:10.1016/S0065-3160(06)41004-2

11. Villano, S. M.; Kato, S.; Bierbaum, V. M. J. Am. Chem. Soc. 2006, 128, 736-737. doi:10.1021/ja057491d

12. Gronert, S.; Fagin, A. E.; Wong, L. J. Am. Chem. Soc. 2007, 129, 5330-5331. doi:10.1021/ja070093

13. Poirier, R. A.; Wang, Y.; Westaway, K. C. J. Am. Chem. Soc. 1994, 116, 2526-2533. doi:10.1021/ja00085a037

14. Yamataka, H.; Ando, T.; Nagase, S.; Hanamura, M.; Morokuma, K. J. Org. Chem. 1984, 49, 631-635. doi:10.1021/jo00178a010

15. Zhao, X. G.; Tucker, S. C.; Truhlar, D. G. J. Am. Chem. Soc. 1991, 113, 826-832. doi:10.1021/ja00003a015

16. Crumpler, T. B.; Yoh, J. H. Chemical Computations and Errors; John Wiley: New York, NY, 1940; p 178.

17. Hoque, M. E. U.; Dey, S.; Guha, A. K.; Kim, C. K.; Lee, B.-S.; Lee, H. W. J. Org. Chem. 2007, 72, 5493-5499. doi:10.1021/jo0700934

18. Hoque, M. E. U.; Dey, N. K.; Kim, C. K.; Lee, B.-S.; Lee, H. W. Org. Biomol. Chem. 2007, 5, 3944-3950. doi:10.1039/b713167d

19. Dey, N. K.; Hoque, M. E. U.; Kim, C. K.; Lee, B.-S.; Lee, H. W. J. Phys. Org. Chem. 2008, 21, 544-548. doi:10.1002/poc.1314

20. Dey, N. K.; Hoque, M. E. U.; Kim, C. K.; Lee, B.-S.; Lee, H. W. J. Phys. Org. Chem. 2009, 22, 425-430. doi:10.1002/poc.1478

21. Hoque, M. E. U.; Guha, A. K.; Kim, C. K.; Lee, B.-S.; Lee, H. W. Org. Biomol. Chem. 2009, 7, 2919-2925. doi:10.1039/b903148k

22. Barai, H. R.; Lee, H.-W. Bull. Korean Chem. Soc. 2011, 32, 1939-1944. doi:10.5012/bkcs.2011.32.6.1939

23. Hoque, M. E. U.; Lee, H. W. Bull. Korean Chem. Soc. 2012, 33, 1879-1884. doi:10.5012/bkcs.2012.33.6.1879

24. Dey, N. K.; Kim, C. K.; Lee, H. W. Org. Biomol. Chem. 2011, 9, 717-724. doi:10.1039/c0ob00517g

25. Jencks, W. P.; Brant, S. R.; Gandler, J. R.; Fendrich, G.; Nakamura, C. J. Am. Chem. Soc. 1982, 104, 7045-7051. doi:10.1021/ja00389a027

26. Onyido, I.; Swierczek, K.; Purcell, J.; Hengge, A. C. J. Am. Chem. Soc. 2005, 127, 7703-7711. doi:10.1021/ja0501565
27. Jencks, W. P. Chem. Rev. 1985, 85, 511-527. doi:10.1021/cr00070a001

28. Bernasconi, C. F. Acc. Chem. Res. 1987, 20, 301-308. doi:10.1021/ar00140a006

29. Bernasconi, C. F. Adv. Phys. Org. Chem. 1992, 27, 119-238. doi:10.1016/S0065-3160(08)60065-9

30. Adhikary, K. K.; Lee, H. W.; Lee, I.-C. Bull. Korean Chem. Soc. 2003, 24, 1135-1140. doi:10.5012/bkcs.2003.24.8.1135

\section{License and Terms}

This is an Open Access article under the terms of the Creative Commons Attribution License

(http://creativecommons.org/licenses/by/2.0), which permits unrestricted use, distribution, and reproduction in any medium, provided the original work is properly cited.

The license is subject to the Beilstein Journal of Organic Chemistry terms and conditions:

(http://www.beilstein-journals.org/bjoc)

The definitive version of this article is the electronic one which can be found at: doi:10.3762/bjoc. 9.68 